\title{
Factors associated with early uptake of COVID-19 vaccination among healthcare workers in Azerbaijan, 2021
}

\author{
Jason Doran ${ }^{1}$, Nabil Seyidov ${ }^{2}$, Samir Mehdiyev², Girogia Gon ${ }^{3}$, Esther Kissling ${ }^{4}$, Trent \\ Herdman $^{1}$, Javahir Suleymanova ${ }^{3}$, Ana Paula Couthino Rehse ${ }^{3}$, Richard Pebody ${ }^{3}$, Mark \\ Katz $^{3}$, and Gahraman Hagverdiyev ${ }^{2}$ \\ ${ }^{1}$ UK Health Security Agency \\ ${ }^{2}$ Centre of Public Health and Reforms of the Ministry of Health \\ ${ }^{3}$ World Health Organization Regional Office for Europe \\ ${ }^{4}$ EpiConcept
}

February 27, 2022

\begin{abstract}
We evaluated uptake and factors associated with COVID-19 vaccination among health workers (HWs) in Azerbaijan. Among $1,575 \mathrm{HWs}, 73 \%$ had received at least one dose and $67 \%$ received two doses; all received CoronaVac. Factors associated with vaccination uptake included no previous COVID-19 infection, older age, belief in the vaccine's safety, previous vaccination for influenza, having patient-facing roles, and good or excellent health by self-assessment. These findings could inform strategies to increase vaccination uptake as the campaign continues.
\end{abstract}

\section{Hosted file}

Final manuscript.docx available at https://authorea.com/users/462609/articles/558006factors-associated-with-early-uptake-of-covid-19-vaccination-among-healthcare-workersin-azerbaijan-2021

\section{Hosted file}

Figures.docx available at https://authorea.com/users/462609/articles/558006-factorsassociated-with-early-uptake-of-covid-19-vaccination-among-healthcare-workers-inazerbaijan-2021 